\title{
Transformational Leadership in the Hospitality Industry
}

\author{
Timothy R. Hinkin \\ School of Hotel Administration \\ Cornell University \\ Ithaca, NY 14853 \\ J. Bruce Tracey \\ School of Hotel Administration \\ Cornell University \\ Ithaca, NY 14853
}

\begin{abstract}
In recent years, the hospitality industry has undergone major changes both within the industry and in its operating environment. Researchers have posited that in an environment of change, as described above, a visionary, or leadership style, would be most appropriate. The study, reported here, compared the use of transformational leadership style with the more traditional transactional style, and examined the effects of transformational leadership on individual and organizational outcomes in a hotel management organization. Results suggest that transformational leadership both impacts perceptions of leadership effectiveness and subordinate satisfaction, and clarifies the direction and mission of the organization.
\end{abstract}

KEYWORDS: transformational, visionary, leadership. 


\section{Transformational Leadership in the Hospitality Industry}

After several decades of relative stability and steady growth, the recent history of the hospitality industry has been characterized by increasing complexity and a dynamic rate of change. Continuing stagnant economic conditions; merger, acquisition, and divestiture activity; overbuilding; a boom in the gaming segment; labor shortages; and an increasingly diverse workforce have resulted in considerable industry turbulence (Dobyns \& Crawford-Mason, 1991; Elder \& Peters, 1987). The demands placed on leaders in the hospitality industry have increased because the operating environment is less predictable. It is in this type of environment that transformational leadership is most needed, with the challenge to "both find and create a vision that is in some way better than the old one and to encourage others to share that dream” (Tichy \& Devanna, 1986, p. 122).

Burns (1978) proposed that the leadership process occurs in one of two ways - either transactionally or transformationally. Transactional leadership emphasizes the clarification of goals, work standards, assignments, and equipment. The focus is on task completion, with compliance based upon the use of incentives and rewards to appeal to the self-interest of followers (Bass, 1985). The transactional leader resists change and concentrates on attempting to maintain the status quo (Bass, Waldman, Avolio, and Bebb, 1987). In contrast, Burns (1978) characterized transformational leaders as those who motivate followers by appealing to higher ideals and moral values. Yukl (1989) refered to transformational leadership as "the process of influencing major changes in the attitudes and assumptions of organization members and building commitment for the organization's mission or objectives” (p. 204). Bass $(1985,1990)$ and his colleagues (Bass \& Avolio, 1989; Seltzer \& Bass, 1990) have extended the work of Burns (1978) and have proposed that transformational leadership is comprised of three components. First, is charisma, which is based on a follower's respect and admiration for the leader, as well as confidence in the leader's vision and values. Second, is individualized consideration, the degree to which the leader shares the individual follower's concerns and developmental needs. Third, is intellectual stimulation, the extent to which the leader provides followers with interesting and challenging tasks and encourages them to solve problems in their own way.

Transformational leaders, according to Seltzer and Bass (1990), engender feelings of 
trust, loyalty, and respect from followers by: (1) generating awareness and acceptance of the purpose and mission of the organization, (2) inducing them to transcend their own self-interest for the sake of the organization, and (3) activating their higher-order needs. It is the responsibility of the transformational leader to provide for followers a clear and accurate understanding of their task and purpose (Atwater \& Bass, 1993). The vision provided by a transformational leader inspires followers by giving their work meaning and making them feel a part of the enterprise. It helps people understand what is good or bad, important or unimportant in the organization, and serves to enhance the speed and quality of decision making, increase initiative, and broaden employee discretion (Bennis \& Nanus, 1985).

Although theoretical development and discussion have been extensive, empirical research on transformational leadership has been limited (Yukl, 1989). Results examining the relationships between transformational leadership and organizational outcomes have been limited to a small number of contexts and a limited number of variables. One finding that seems to be well supported in several case studies is that a transformational leader will often emerge during an organizational crisis or major organizational transition (Bass, 1985). It is at this juncture that the leader convinces others that the old ways of doing things are no longer effective and she or he is then able to alter the direction of the organization by redefining the mission (Roberts, 1984; Tichy \& Devanna, 1986). Another finding from case studies is that the vision must be reinforced by the behavior of the leader in order to be effective (Bennis, 1984; Schein, 1985). To maintain their credibility, and the trust and respect of followers, the leaders' actions must be consistent with their words. Transformational leadership has been associated with the effective implementation of change in a variety of settings (Bass, 1985; Avolio \& Bass, 1987; Hater \& Bass, 1988; Roberts, 1984; Tichy \& Devanna, 1986). Finally, laboratory and field studies have produced evidence that subordinates of transformational leaders will experience higher performance, greater satisfaction, and less role conflict than subordinates of transactional leaders (Howell \& Frost, 1989; Keller, 1992; Seltzer \& Bass, 1990).

\section{THE CURRENT STUDY}

Most studies of transformational leadership have examined CEOs of major corporations in manufacturing settings. Organizations in the service industries have gone largely unexamined. Although one would not expect major differences in the importance of leadership in different 
types of industries, in the labor intensive service industries the performance of an organization rests more in the hands of employees (Dittmer \& Griffin, 1993; Martin \& Lundberg, 1992). Bourgeois (1980) found that employee efficiency and morale are more critical to the success of service firms than to manufacturing or high technology firms. In the absence of machinery and other forms of technology that reduce the need for human labor, management in the hospitality industry is more dependent on subordinates for increased productivity than their peers in other industries (Angelo \& Vladimir, 1992). This dependency relationship, together with the turbulent conditions currently existing in the industry, places a great deal of importance on the role of the transformational leader in establishing the vision of the organization and in motivating employees in the pursuit of that vision.

The study reported here examined the relationships among leadership style, leader effectiveness, subordinate satisfaction with the top management group, and several other outcome variables in a U. S. hotel management company. The study extends prior research in three primary ways:

1. It was conducted in the labor intensive hospitality industry.

2. It focused on top-level management, who determine policy that is visible and impacts all organizational members.

3. The measures provided the opportunity to examine both previously tested and theorized relationships.

\section{HYPOTHESES}

Previous studies have found that significant positive relationships exist between transformational leadership and subordinate satisfaction and leader performance measures (Yukl, 1989). However, most of the previous research has focused on the benefits of transformational leadership without comparing its effects with the more traditional, or transactional, leadership style. Bass (1985) suggested that the two types of leadership are not mutually exclusive, and that transactional leadership might be appropriate in certain situations, with transformational leadership providing an additive effect. Hollander (1993) also viewed transformational leadership as an extension of transactional leadership. His perspectives were consistent with contingency leadership theories that suggest that subordinate skill level, knowledge of the task, and other situational factors may dictate the appropriate type of leadership (e.g., Fiedler, 1986; 
Hersey \& Blanchard, 1984; Stogdill, 1974).

Based on the results of prior studies (e.g., Bass, 1985; Bennis \& Nanus, 1985; Tichy \& Devanna, 1986), it could be expected that transformational leadership would be particularly salient to followers during times of growth and change. It can be hypothesized, therefore, that a leader who was perceived to be exhibiting transformational behaviors would be evaluated more positively than one who did not:

Hypothesis 1: Transformational leadership is a stronger predictor of employee-that is, follower-satisfaction with the leader than transactional leadership.

Hypothesis 2: Transformational leadership is a stronger predictor of leadership effectiveness than transactional leadership.

There is another gap in research on transformational leadership: Many relevant variables other than satisfaction and effectiveness have yet to be examined. As noted earlier, it has been proposed (Yukl, 1989) that transformational leaders formulate a vision, develop commitment to it from internal and external stakeholders, implement strategies to realize the vision, and embed their values in the culture of the organization. The leader must provide followers with a sense of what is possible and motivate them to work toward the future that the leader envisions (Bennis \& Nanus, 1985; Tichy \& Devanna, 1986). Thus, through words and actions, effective transformational leaders must provide a clear direction for individuals as they attempt to help the organization achieve its overall goals. The ability to accomplish this may be largely a function of the situation and the congruence of their vision and values with those of their followers (Bass, 1985; House, 1977; Tichy \& Devanna, 1986). In order to do this, leaders must have a value system consistent with their followers, and the mission must be accepted by the followers. Value congruence and mission clarity are based in part on a leader's ability to articulate and openly communicate the mission (Atwater \& Bass, 1993). This sense of purpose will, in turn, positively impact follower perceptions of leadership, satisfaction, and performance.

To test these theorized relationships, a model proposing that leadership style impacts subordinate affect and perceptions of effectiveness not only directly, but through mediating variables as well, was developed (see Figure 1).

Prior research has shown that subordinates of transformational leaders will experience greater satisfaction than subordinates of transactional leaders (Howell \& Frost, 1989; Keller, 1992; Seltzer \& Bass, 1990). In addition, Atwater and Bass(1993) and Tichy and Devanna 
(1986) have stressed that one of the key roles of transformational leaders is to clarify the mission of the organization for the followers.

Clarity of purpose should relate positively to follower satisfaction and to perceptions of leader effectiveness. Therefore, the following hypotheses were proposed:

Hypothesis 3: Transformational leadership has a positive effect on mission clarity. Hypothesis 3a: Mission clarity has a positive effect on employee satisfaction, beyond that accounted for by transformational leadership.

Hypothesis 3b: Mission clarity has a positive effect on leadership effectiveness, beyond that accounted for by transformational leadership.

Another important responsibility of the transformational leader is to clarify role expectations for organizational members (Atwater\& Bass, 1993; Bennis \& Nanus, 1985). Role clarity has been shown to be strongly associated with subordinate satisfaction (Rizzo, House, \& Lirtzman, 1970). Subordinates of transformational leaders also have been shown to experience less role conflict than subordinates of transactional leaders (Howell \& Frost, 1989; Keller, 1992; Seltzer \& Bass, 1990). Thus, the following hypotheses were examined:

Hypothesis 4: Transformational leadership has a positive effect on role clarity.

Hypothesis 4a: Role clarity has a positive effect on employee satisfaction beyond that accounted for by transformational leadership.

Hypothesis $4 b$ : Role clarity has a positive effect on leadership effectiveness, beyond that accounted for by transformational leadership.

To be effective, the transformational leader must convey his or her vision in a manner that it understood and accepted by followers (House, 1977). "A person with vision who cannot articulate beliefs and values and inspire others is a dreamer, not a leader” (Snyder, Dowd, \& Houghton, 1994, p. 20). One of the objectives of the transformational leader is to foster an environment where communication flows freely throughout the organization (Tichy \& Devanna, 1986).

By understanding the need for change and being involved in the organizational transformation, followers should view leaders positively and feel comfortable in an environment of change. Therefore, the following hypotheses are proposed:

Hypothesis 5: Transformational leadership has a positive effect on perceptions of open communication. 
Hypothesis 5a: Open communication has a positive effect on employee satisfaction, beyond that accounted for by transformational leadership.

Hypothesis 5b: Open communication has a positive effect on leadership effectiveness, beyond that accounted for by transformational leadership.

\section{METHOD}

\section{Sample}

The organization under examination has experienced rapid growth in the last several years under adverse environmental conditions. It currently operates and/or owns about 60 hotels of various sizes located in all regions of the United States, with a total of more than 5,000 employees. There were a total of 141 responses used in this study, including both corporate employees and general managers. The top management group which included five partners- that is, principal investors — and six regional vice-presidents, represented the leadership in this organization, and served as the focus or referent in this study.

The participants responded to questionnaires on a voluntary basis and were assured that their individual responses would remain confidential. Each returned the completed questionnaires directly to an independent consultant conducting other business with the organization. The response rate was $75 \%$ for the corporate employee group and $84 \%$ for the general manager group.

The average age of the respondents was 36, and 54\% were males. Most of the individuals (61 \%) had been in their current job longer than one year, and most (62\%) had at least an undergraduate college degree. There were no significant differences between the corporate employees and general managers on any of the demographic information that was collected.

\section{Procedure for Data Collection}

For the general managers ( $n=46$ ), the questionnaires were distributed and collected by the independent consultant during each general manager's annual meeting. The referent for leadership was each general manager's regional vice-president, and there were an average of eight responses per vice-president. The measures are described in more detail below.

For the corporate employees $(n=45)$, the questionnaires were distributed and collected by the independent consultant over two administrations. For the first administration, all measures 
except the transformational leadership and effectiveness measures were collected. The remaining two measures were collected four weeks later.

During the second administration, the corporate employees were asked to complete up to five questionnaires, one for each of the five partners of the organization. Each partner also filled out a questionnaire for each of the other partners. The corporate employees completed the second questionnaire only if they had at least daily contact with one or more of the partners. A total of 95 questionnaires were completed, averaging 19 responses per partner.

\section{Measures}

\section{Transformational Leadership}

Six scales from Form 5-X of the Multifactor Leadership Questionnaire (MLQ), developed by Bass (1990), were used. The scales assessed six dimensions of leadership, including attributed charisma, intellectual stimulation, individual consideration, active management-by-exception, passive management-by-exception, and contingent reward. Bass proposed that, conceptually, the first three scales represent transformational leadership, while the remaining three represent transactional leadership.

The items asked respondents to indicate how frequently his or her immediate supervisor demonstrated the leadership behavior described. Each scale had 7 to 10 items. The response choices ranged from (1) not at all, to (5) frequently, if not always. Coefficient alpha internal consistency reliabilities exceeded .90 for the overall transformational leadership measure and .80forthe overall transactional leadership measure-well above the .70 level suggested as acceptable by Nunnally (1978). A sample item from each scale is listed below:

1. Attributed charisma-“Remains calm during crisis situations."

2. Intellectual stimulation- "Emphasizes the value of questioning assumptions.”

3. Individual consideration — “Treats me as an individual rather than just a member of a group.”

4. Active management-by-exception- “Focuses attention on irregularities, mistakes, exceptions, and deviations from standards."

5. Passive management-by-exception- “It requires a failure to meet an objective for him or her to take action.”

6. Contingent reward-“Gives me what I want in exchange for my support.” 


\section{Mission Clarity}

Because no measure of mission clarity existed, a four-item measure was developed by the authors specifically for the current study. The items were carefully generated to adequately sample the domain of interest. Specifically, the words “mission, goal, purpose, and plan” were incorporated into the items, based on the discussion of mission by Thompson and Strickland (1981). Coefficient alpha internal consistency reliability for the measure was .81. The items asked respondents to indicate the extent to which they agreed with the following: the organization has a well-defined mission, the goals of this organization are communicated effectively; the overall purpose of this organization is clearly understood; and the strategic plan of this organization is well defined. The response choices ranged from (1) strongly disagree, to (5) strongly agree.

\section{Role Clarity}

The six-item role clarity measure developed by Rizzo, House, and Lirtzman (1970) was used. The items asked respondents to indicate the extent to which several aspects of their job were understood. Coefficient alpha internal consistency reliability was .79. An example item was, “I feel certain about how much authority I have.” The response choices ranged from (1) very false, to (7) very true.

\section{Openness of Communication}

The five-item openness of communication measure developed by O'Reilly and Roberts (1976) was used. These items asked respondents to indicate the extent to which they agreed with statements regarding communication in their organization. Coefficient alpha internal consistency reliability was .83. An example item was, "It is easy to ask advice from any member of this group.” The response choices ranged from (1) strongly disagree, to (7) strongly agree.

\section{Effectiveness}

A six-item scale was developed by the authors specifically for the current study. The items asked respondents to rate the effectiveness of the leader on the following: technical competence; interpersonal skills; procedural justice; organizational influence; communication; and goal clarification. Coefficient alpha internal consistency reliability was .88. These items were used to assess multiple dimensions of a single, broadly defined, underlying construct, (cf., Campbell, Dunnette, Lawler, \& Weick, 1970). The response choices ranged from (1) highly ineffective, to (7) highly effective. 


\section{Leader Satisfaction}

A three-item subscale of the supervisor satisfaction scale from the Minnesota Satisfaction Questionnaire (Weiss, Dawis, England, \& Lofquist, 1967) was used. The items asked respondents to rate the extent to which they were satisfied with the leader. The scale had an internal consistency reliability of .78. An example item was, “The way (referent) handles his/her subordinates.” The response choices ranged from (1) very dissatisfied, to (5) very satisfied.

\section{Analyses}

The three measures specifically designed or modified for this study (mission clarity, satisfaction, and effectiveness) were subjected to principal components factor analysis using a maximum likelihood extraction. Internal consistency reliabilities (Cronbach’s alpha) were computed for all scales. All measures used in the study were then intercorrelated to examine consistency of results with previous research. Finally, a series of bivariate, multiple, and hierarchical regressions were conducted to test for hypothesized main effects and mediating effects.

\section{RESULTS}

\section{Descriptive Statistics}

The means, standard deviations, internal consistency reliability estimates, and intercorrelations among all the measures are shown in Table 1. All factor analyses resulted in one-factor solutions with the Eigen values and total explained variance of 2.14 and $53.6 \%$ for mission clarity, 1.91 and $63.8 \%$ for satisfaction, and 3.37 and $56.2 \%$ for effectiveness, respectively. As noted earlier, all internal-consistency estimates were adequate, ranging from 0.78 to 0.92 (Nunnally, 1978).

\section{Correlations and Regressions}

The results from the correlation analyses showed that there was a very small negative (.12 , not statistically significant) relationship between transformational and transactional leadership. Transformational leadership was significantly, positively related to satisfaction with the leader, ratings of leader effectiveness, mission clarity, role clarity, and openness of communication, while transactional leadership showed no significant relationships with any of these variables. Mission clarity, role clarity, and openness of communication were all positively related with satisfaction with the leader and leader effectiveness. 
A series of bivariate, multiple, and hierarchical regression analyses were conducted to examine the extent to which: (1) transformational leadership accounted for more variance in leader satisfaction and effectiveness than transactional leadership; (2) transformational leadership predicted perceptions of mission clarity, role clarity, and openness of communication; and (3) mission clarity, role clarity, and openness of communication accounted for additional variance in satisfaction and effectiveness, beyond that accounted for by transformational leadership. Cohen and Cohen (1975) recommended the use of hierarchical regression when there is theoretical support for describing the sequence of variables to be included in a regression analysis - that is, to test for mediating effects. As stated by hypotheses 3b, 4b, and 5b, it was proposed that mission clarity, role clarity, and openness of communication would mediate the relationship between transformational leadership and perceptions of satisfaction and effectiveness.

The results from the multiple regression analyses showed that, when aggregated measures of transformational and transactional leadership were entered simultaneously to predict leader satisfaction and effectiveness, only transformational leadership had a significant beta weight in the regression equations. Transformational leadership accounted for $16 \%$ of the variance in leader satisfaction ( $\mathrm{F}=16.79 ; \mathrm{p}<.01$ ), and accounted for $73 \%$ of the variance in effectiveness ratings ( $\mathrm{F}=273.07 ; p<.01)$. Thus, on the basis of the correlation and regression analyses, hypotheses 1 and 2 were fully supported.

To test hypotheses 3, 4, and 5, mission clarity, role clarity, and open communication were treated as separate outcomes of transformational leadership. For each outcome, transformational leadership accounted for a significant proportion of variance: $14 \%$ of the variance in mission clarity $(\mathrm{F}=16.44 ; \mathrm{p}<.01) ; 6 \%$ of the variance in role clarity $(F=5.63 ; \mathrm{p}<.01)$; and $9 \%$ of the variance in openness of communication ( $\mathrm{F}=9.82 ; \mathrm{p}<.01)$. Therefore, based on the correlation and regression analyses, hypotheses 3,4 , and 5 were fully supported.

To test hypotheses 3a, 4a, and 5a, a series of hierarchical regression analyses were conducted using leader satisfaction as the dependent variable. Transformational leadership was entered first, followed by mission clarity, role clarity, and openness of communication, each entered separately as step two. When mission clarity was added into the equation, an additional $4 \%$ of the variance in leader satisfaction was accounted for $(\mathrm{F}=11.02 ; \mathrm{p}<.01)$. When role clarity was added, an additional $29 \%$ of the variance was accounted for $(\mathrm{F}=35.70$; $\mathrm{p}<.01)$. When 
openness of communication was added, an additional 9\% of the variance was accounted for 4.55; $\mathrm{p}<$.01). In each analysis, transformational leadership had a significant beta weight in the final regression equation. Therefore, based on the correlation and regression analyses, hypotheses 3a, For hypotheses 3b, 4b, and 5b, no additional variance in leader effectiveness, beyond that explained by transformational leadership was accounted for when mission clarity, role clarity, and openness of communication were each added separately in step two of the hierarchical regression analyses. Although the zeroorder correlations between these three variables and leader effectiveness were significant, the hierarchical regression analyses do not support hypotheses 3b, 4b, and 5b. The results from all of the regression analyses are shown in Tables 2 and 3.

\section{DISCUSSION}

Bass (1985) suggested that an individual manager may use both transformational and transactional leadership. The relationship between the two types of leadership has not yet been empirically examined, but the findings of the current study challenge that proposition. The correlation between the two types of leadership was nonsignificant, and only transformational leadership predicted satisfaction and effectiveness. In fact, the small negative relationship between transformational and transactional leadership suggests that few, if any, managers in the sample demonstrated both types of leadership. In addition, the nonsignificant relationship between transactional leadership and the dependent variables under examination suggests that the more traditional leadership style is not viewed favorably in this context and environment.

The results from this study support previous research which has shown that transformational leadership has a direct impact on perceptions of leader satisfaction and effectiveness outcomes. Moreover, this study extends previous findings by showing that transformational leadership may also have an indirect impact on perceptions of satisfaction through its impact on mission clarity, role clarity, and openness of communication. The latter finding is especially important in that it provides some additional detail as to the underlying reasons how and why transformational leaders influence follower perceptions.

It was noted earlier that characteristics of the work context may influence the degree to which transformational leadership is viewed positively. In the current study, it was found that mission clarity, role clarity, and openness of communication each added additional explanatory variance for perceptions of leader satisfaction. This suggests that one reason followers are 
satisfied with a transformational leader is that such leaders clarify the organizational mission, and articulate the follower's role in accomplishing that mission. The clarification and articulation of the organizational mission and follower roles may be achieved through effective, open communication. In other words, one could argue that followers will be satisfied with transformational leaders only when they openly communicate the organizational mission and their role in fulfilling it. This finding is consistent with the theoretical propositions of Tichy and Devanna (1986).

Mission clarity, role clarity, and openness of communication did not add any additional explanatory variance in perceptions of effectiveness, beyond that accounted for by transformational leadership. Transformational leadership demonstrated a much stronger main effect on effectiveness ratings than on satisfaction. However, given the strength of the main effect, it was unlikely that any additional variance in effectiveness ratings could be accounted for by any additional variable.

The findings highlight the importance of examining multiple, yet distinct, outcomes of transformational leadership. As supported in past research, transformational leadership had a direct impact on both subordinate feelings and evaluation of leader effectiveness. However, the moderate correlation between satisfaction with the leader and leader effectiveness $(.39 ; p<.01)$ suggests that respondents were able to separate their feelings toward leaders from their evaluation of leader effectiveness. Further, transformational leadership separately predicted perceptions of mission clarity, role clarity, and openness of communication. These three outcomes were also moderately intercorrelated (ranging from .38 to .52; $p<.01$ ). Thus, it appears that transformational leadership influences a broad range of follower perceptions. These perceptions may, in turn, influence follower behavior and performance which contribute to the overall success of an organization.

\section{CONCLUSION}

Transformational leadership demonstrated by the top management team was viewed very positively in an organization undergoing dramatic growth and change. As proposed by Bass (1985) and Tichy and Devanna (1986), it appears that organizational success in a dynamic, changing environment may depend on the leadership style of its top managers. However, it could be argued that transformational leadership could also be beneficial in times of stability. As the 
hospitality industry begins to rebound, as it now appears to be doing, there may be a dangerous sense of security and complacency among managers. When changes in the environment are gradual, leaders often fail to recognize threats to their organization and continue to conduct business in a routine manner (Bennis \& Nanus, 1985). Thus, transformational leadership may be needed to change the status quo and bring about necessary change. Additional research is needed to determine the extent to which transformational leadership influences important individual and organizational outcomes under different environmental conditions.

Lack of a clear vision is a major reason for the declining effectiveness of many organizations in recent years (Bennis \& Nanus, 1985; Peters \& Waterman, 1982). According to Yukl (1989), "During the past two decades, many organizations have been unable to maintain a clear vision, due in part to changing social values, internationalization of business, rapid technological change, increased diversification caused by mergers and acquisitions, and a shortterm, bottom-line mentality among many executives and powerful external coalitions [e.g., stockholders, owners, bankers]" (p. 222). it is unlikely that the hospitality industry will become any more stable or less complex in the future. As such, transformational leadership-the ability to create and communicate a vision and adapt the organization to a rapidly changing environment—may be the most crucial leadership skill in the years to come. 


\section{ACKNOWLEDGEMENT}

The authors would like to thank Professor Peter Rainsford from the School of Hotel

Administration, Cornell University, for his assistance in the data collection for this study. This

research was partially funded by support from the Center for Hospitality Research, School of Hotel Administration, Cornell University. 
Table 1. Results of Means, Standard Deviations, Internal Consistency Reliability Estimates, and Intercorrelations for Measures of Leadership—and Dependent Variables.

\begin{tabular}{|c|c|c|c|c|c|c|c|c|c|c|}
\hline & Mean & SD & $\alpha$ & 1 & 2 & 3 & 4 & 5 & 6 & 7 \\
\hline $\begin{array}{l}\text { Transformational } \\
\text { Leadership }\end{array}$ & 3.33 & .76 & .96 & - & & & & & & \\
\hline $\begin{array}{l}\text { Transactional } \\
\text { Leadership }\end{array}$ & 2.45 & .50 & .81 & -.12 & - & & & & & \\
\hline Mission Clarity & 3.55 & .78 & .81 & $.37^{* *}-$ & -.04 & - & & & & \\
\hline Role Clarity & 4.93 & 1.07 & .79 & $.25^{*}$ & .23 & $.43^{* *}$ & - & & & \\
\hline $\begin{array}{l}\text { Openness of } \\
\text { Communication }\end{array}$ & 5.07 & 1.30 & .83 & $.29^{*}$ & .02 & $.38^{* *}$ & $.52^{* *}$ & - & & \\
\hline $\begin{array}{l}\text { Leader } \\
\text { Satisfaction }\end{array}$ & 3.47 & .98 & .78 & $.40^{* *}$ & .05 & $.34^{* t}$ & $.63^{* *}$ & $.41^{\text {t* }}$ & - & \\
\hline $\begin{array}{l}\text { Leader } \\
\text { Effectiveness }\end{array}$ & 4.99 & 1.22 & .88 & $.85^{* *}$ & -.17 & $.39^{* *}$ & $.27^{*}$ & $.22^{*}$ & $.39^{* *}$ & - \\
\hline
\end{tabular}


Table 2. Results from Hierarchical Regression Analyses of the Relationship of Transformational Leadership, Mission Clarity, Role Clarity, and Openness of Communication, with Satisfaction with Leadership, with Leadership and Leader Effectiveness.

\begin{tabular}{|c|c|c|c|c|c|}
\hline Dependent Variable & Independent Variables & beta & s.e. & $\boldsymbol{F}$ & $\boldsymbol{F}^{2}$ \\
\hline \multicolumn{6}{|l|}{ Leader satisfaction } \\
\hline & Transformational leadership & $.41^{* *}$ & .13 & & \\
\hline & Transactional leadership & .10 & .19 & 8.78 & .17 \\
\hline \multicolumn{6}{|l|}{ Leader effectiveness } \\
\hline & Transformational leadership & $.84^{* *}$ & .09 & & \\
\hline & Transactional leadership & -.06 & .13 & 129.80 & .73 \\
\hline \multicolumn{6}{|l|}{ Mission clarity } \\
\hline & Transformational leadership & $.37^{* *}$ & .09 & 16.44 & .14 \\
\hline \multicolumn{6}{|l|}{ Role clarity } \\
\hline & Transformational leadership & $.25^{*}$ & .15 & 5.63 & .06 \\
\hline \multicolumn{6}{|c|}{ Openness of communication } \\
\hline & Transformational leadership & $.29 * *$ & .16 & 9.82 & .09 \\
\hline
\end{tabular}


Table 3. Results of Hierarchical Regression Analyses of the Relationship of Transformational Leadership, Mission Clarity, Role Clarity, and Openness of Communication, with Satisfaction with Leadership, And Leader Effectiveness.

\begin{tabular}{llllll|}
\hline Dependent Variables & Independent Variables & beta & s.e. & $F$ & $\boldsymbol{R}^{2}$ \\
\hline Leader Satisfaction & & & & & \\
STEP 1: & Transformational leadership & $.41^{* *}$ & .13 & 16.80 & .16 \\
STEP 2: & Mission clarity & $.22^{* *}$ & .13 & 11.02 & .20 \\
STEP 1: & Transformational leadership & $.41^{* *}$ & .13 & 16.80 & .16 \\
STEP 2: & Role clarity & $.56^{* *}$ & .08 & 35.70 & .45 \\
STEP 1: & Transformational leadership & $.41^{* *}$ & .13 & 16.80 & .16 \\
STEP 2: & Openness of communication & $.32^{* *}$ & .08 & 14.55 & .25 \\
& & & & & \\
Leader Effectiveness & & & & & \\
STEP 1: & Tranformational leadership & $.86^{* *}$ & .14 & 273.06 & .73 \\
STEP 2: & Mission clarity & .08 & .08 & 139.20 & .73 \\
STEP 1: & Transformational leadership & $.86^{* *}$ & .14 & 273.06 & .73 \\
STEP 2: & Role clarity & .06 & .07 & 116.12 & .73 \\
STEP 1: & Transformational leadership & $.86^{* *}$ & .14 & 273.06 & .73 \\
STEP 2: & Openness of communication & -.03 & .05 & 135.90 & .73 \\
\hline $\begin{array}{l}\text { Note. ** } p<.01 ; \text { For each analysis, transformational leadership had a significant beta } \\
\text { weight in the final regression equation. }\end{array}$ & & & & & \\
\hline
\end{tabular}


Figure 1. The Hypothesized Relationships between Transformational Leadership, Mediating Variables, and Outcome Variables.

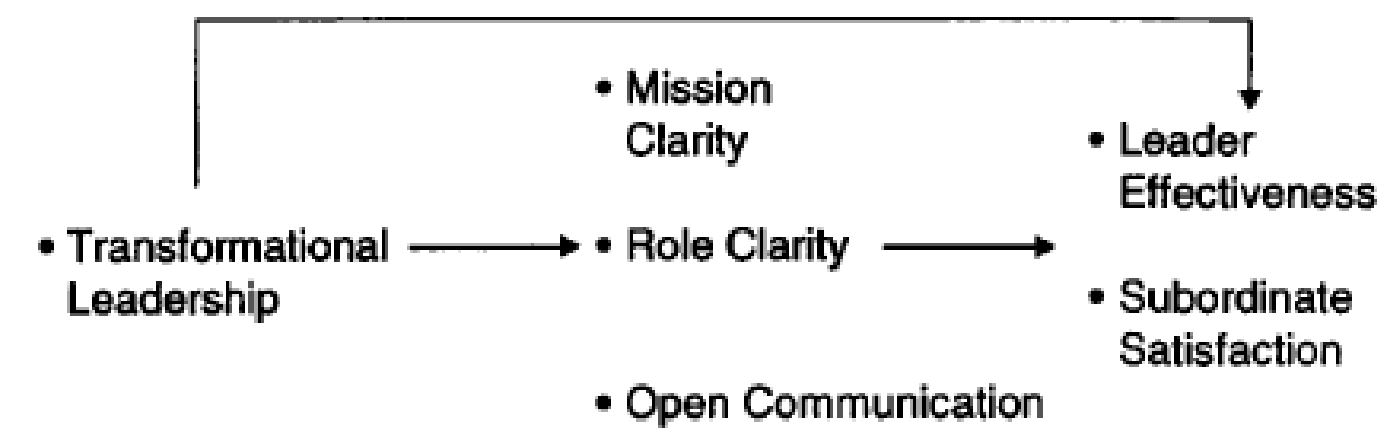




\section{REFERENCES}

Angelo, R. M., \& Vladimir (1992). Hospitality today: An introduction. East Lansing, Ml: Educational Institute of the American Hotel and Motel Association.

Atwater, L. E., \& Bass, B. M. (1993). Transformational leadership in teams. In B. M. Bass \& B. J. Avolio (Eds.), Improving organizational effectiveness through transformational leadership (pp. 48-77). Thousand Oaks, CA: Sage.

Bass. B. M. (1985). Leadership and performance beyond expectations. New York: The Free Press.

Bass. B. M. (1990). From transactional to transformational leadership: Learning to share the vision. Organizational Dynamics, 18, 19-31.

Bass, B. M., \& Avolio, B. J. (1989). Manual for the multifactor leadership questionnaire. Palo Alto: Consulting Psychologists Press.

Bass, B. M., \& Avolio, B. J. (1990). Multifactor leadership questionnaire. Palo Alto: Consulting Psychologists Press.

Bass, B. M., Waldman, D. A., Avolio, B.J., \& Bebb, M. (1987). Transformational leaders: The falling dominoes effect. Group and Organizational Studies, 12,73-87.

Bennis, W. G. (1984). The four competencies of leadership. Training and Development Journal, 38, 14-19.

Bennis, W. G., \& Nanus, B. (1985). Leaders: The strategies for taking charge. New York: Harper \& Row.

Bourgeois, L. J. (1980). Performance and consensus. Strategic Management Journal, 1, 227-248.

Burns, J. M. (1978). Leadership. New York: Harper Row.

Campbell, J. P., Dunnette, M. D., Lawler, E. E., \& Weick, K. E. (1970). Managerial behavior, performance, and effectiveness. New York: McGraw-Hill.

Cohen, J., \& Cohen, M. (1976). Applied multiple regression/correlation analysis for the behavioral sciences. Hillsdale, NJ: Lawrence Erlbaum.

Dittmer, P. R., \& Griffin, G. C. (1993). Dimensions of the hospitality industry. New York: Van Nostrand Reinhold.

Dobyns, L., \& Crawford-Mason, C. (1991). Quality or else: The revolution in world business. Boston: Houghton Mifflin. 
Elder, M., \& Peters, J. (1987). The labor challenge. In P. E. Diaz \& D. I. Smith (Eds.), The hospitality industry: A management profile (pp. 98-116). Dubuque, IA: Kendall Hunt.

Fiedler, F. (1986). The contribution of cognitive resources to the leadership process. Journal of Applied Psychology, 16, 532-548.

Hater, J. J., \& Bass. B. (1988). Superiors' evaluations and subordinates’ perceptions of leadership. Journal of Applied Psychology, 73, 695-702.

Hersey, P., \& Blanchard, K. H. (1984). The management of organizational behavior (4th ed.) Englewood Cliffs, NJ: Prentice-Hall.

House. R. J. (1977). A 1976 theory of charismatic leadership. In J. G. Hunt \& L. L. Larson (Eds.), Leadership: The cutting edge (pp. 189-207). Carbondale, IL: Southern Illinois University Press.

Howell, J. M., \& Frost, P. (1989). A laboratory study of charismatic leadership. Organizational Behavior and Human Decision Process, 43, 243-269.

Keller, R. T. (1992). Transformational leadership and the performance of research and development project groups. Journal of Management, 18, 489-502.

Martin, R. J., \& Lundberg, D. E. (1992). Human relations for the hospitality industry. New York: Van Nostrand Reinhold.

Nunnally, J. C. (1978). Psychometric theory (2nd ed.). New York: McGraw-Hill.

Peters, T. J., \& Waterman, R. H. (1982). In search of excellence: Lessons from America's best run companies. New York: Harper \& Row.

Rizzo, J. R., House, R. J., \& Lirtzman, S. E. (1970). Role conflict and ambiguity in complex organizations. Administrative Science Quarterly, 15,150-163.

Roberts, N. C. (1984). Transforming leadership: Sources, processes, consequences. Paper presented at the annual Academy of Management meetings, Boston.

Schein, E. H. (1985). Organizational culture and leadership. San Francisco: Jossey-Bass.

Seltzer, J., \& Bass, B. M. (1990). Transformational leadership: Beyond initiation and structure. Journal of Management, 16, 693-704.

Snyder, N. H., Dowd, J. J, \& Houghton, D. M. (1994). Vision, values, and courage: Leadership for quality management. New York: The Free Press.

Stogdill, R. M. (1974). Handbook of leadership: A survey of the literature. New York: The Free Press. 
Thompson, A. A., \& Strickland, A.J. (1981). Strategy and policy: Concepts and cases. Plano, TX: Business Publications.

Tichy, N. M. \& Devanna, M. A. (1986). The transformational leader. New York: John Wiley \& Sons.

Weiss, D. J., Dawis, R. V., England, G. W., and Lofquist, L. H. (1967). Manual for the Minnesota satisfaction questionnaire. Minneapolis: University of Minnesota, Industrial Relations Center. 